\title{
Ler e recarregar a página: um exercício analítico sobre a reescrita da webnotícia
}

\section{Reading and Reloading Pages: a Brief Analisys of Rewriten Webnews}

\author{
Ana Elisa Ribeiro* \\ CEFET-MG \\ Belo Horizonte - Minas Gerais / Brasil \\ Camila Gonzaga-Pontes** \\ CEFET-MG \\ Belo Horizonte - Minas Gerais / Brasil
}

\begin{abstract}
RESUMO: A notícia escrita na web vem sendo considerada, pelos estudiosos da comunicação, como um gênero com características próprias, que a diferenciam da notícia impressa. A atualização constante, possível na internet, faz com que esse texto noticioso vá sendo reescrito enquanto é apurado. Com base nos conceitos de retextualização e reescrita, apresentamos uma análise de uma webnotícia. Selecionamos um texto factual e salvamos, por meio de um software, todas as suas atualizações (sete, no total) ao longo do dia. A análise dessa notícia, em construção por mais de uma hora, diante dos olhos do leitor, mostra operaçōes de reescrita e questōes de apuração jornalística que podem fazer diferença tanto para os processos de produção noticiosa (um novo paradigma, provavelmente) quanto para as práticas sociais do leitor.
\end{abstract}

PALAVRAS-CHAVE: Webjornalismo; Webnotícia; Reescrita; Retextualização.

ABSTRACT: Webnews have been considered, by communication researchers, as a genre with its own characteristics, which distinguish them from printed news. Constant updating, possible on the Internet, enables that the news are rewritten while the facts are investigated. Based on the concepts of rewriting and retextualization, we present an analysis of one fact reported as webnews. We selected a factual text and, using a software, we saved all updates (seven in total) during a day. The analysis of this report, under construction for more than an hour, in front of the readers' eyes, shows rewriting operations and issues about journalistic investigation that can affect both the news production processes (a new paradigm, probably) and the reader's social practices.

KEYWORDS: Digital Journalism; Webnews; Rewriting; News making.

\footnotetext{
* anadigital@gmail.com

**migonzaga@yahoo.com.br
} 


\section{Considerações iniciais}

Os modos de circulação influenciam a composição dos textos. ${ }^{1}$ Essa é a premissa da qual partimos aqui, uma vez que focalizamos um campo profissional que se vale não apenas dos "veículos" de comunicação, mas também de alguns gêneros textuais bastante especializados. É o caso, por exemplo, da notícia, que tem seus modos de inscrição e circulação bastante estabilizados, ${ }^{2}$ mas que se vê em metamorfose depois das possibilidades dadas por tecnologias digitais, pela mobilidade e pela exibição em telas de diversos tamanhos, por meio de variados dispositivos.

O jornalismo é um dos campos profissionais afetados pelas tecnologias de publicação, considerando "tecnologias de publicação", aqui, os modos de veiculação ou de fazer circularem os textos multimodais que chegam ao leitor/espectador/ ouvinte. Tanto essa relação meio/mensagem é algo central no jornalismo que existem denominaçôes que tomam como eixo justamente "onde" a notícia circula: radiojornalismo, telejornalismo, jornalismo impresso e webjornalismo.

Esta última "etiqueta" do jornalismo, por si só, pressupóe uma diferenciação entre outros jornalismos, produzidos para outros meios, e o jornalismo digital, isto é, na prática jornalística, é diferente produzir uma notícia para o impresso, para o rádio, para a TV ou para a internet. ${ }^{3}$

Essas questôes, no entanto, são tão recentes que sequer o nome dado a esse jornalismo está estabilizado. Mielniczuk (2001) já mencionava um impasse (teórico, inclusive) na nomeação, estando em disputa os nomes: webjornalismo, ciberjornalismo, jornalismo on-line e jornalismo digital. ${ }^{4}$ Analogamente, há os

\footnotetext{
${ }^{1}$ É conhecida a defesa do historiador da leitura Roger Chartier, que trata das questôes que relacionam produção de sentido e suporte/inscrição do texto. As práticas de leitura não são uniformes e mudam em função da materialidade em que estão inscritos. Ver, por exemplo, Chartier $(2001 ; 2002)$.

${ }^{2}$ Importante conhecer o trabalho de Bonini, em que ele aponta as indefiniçóes na conceitualização dos gêneros na área de comunicação. Ver Bonini (2001; 2003; 2003a; 2003b). A produção de Bonini foi comentada e criticada por Marques de Melo (2009), importante pesquisador da Comunicação.

${ }^{3}$ Vide a quantidade de livros cujos títulos prometem ensinar peculiaridades na redação jornalística para TV, rádio ou web, como Paternostro (2006), Salaverría (2005), Nascimento (2009), Jovem Pan (1993), Rodrigues (2006) ou Moherdaui (2007).

${ }^{4}$ No Brasil, atualmente, o nome webjornalismo parece já ser hegemônico, a despeito de vários livros que falam em jornalismo digital. $\mathrm{O}$ termo ciberjornalismo, de matriz espanhola, não chegou a decolar.
} 
autores $^{5}$ que etiquetam também o produto mais típico do jornalismo, isto é, a notícia, que se torna, então, webnotícia. O português João Canavilhas, um desses pesquisadores, e influenciador de muitos estudos no Brasil, aponta a webnotícia como um "produto completamente novo" (2001, p. 1).

E por que razões a webnotícia seria "completamente nova”? A nosso ver, um produto textual que tem como matriz um outro, impresso, não pode ser "completamente" novo, sendo, quando muito, um caso de "inovação incremental" (emprestando um termo às discussões de ciência e tecnologia). Aqui, consideraremos, então, a webnotícia um produto editorial e textual modificado em relação à sua matriz, mas não de maneira "evolutiva" ou linear, originado por um processo que sofreu transformaçōes de cunho tecnológico e social, com raízes firmes na invenção do computador (e de suas affordances) e da difusão de notícias pela internet.

\section{Retextualização e reescrita}

Retextualização e reescrita não são temas novos, havendo trabalhos bastante conhecidos nos estudos de linguagem, tais como, no Brasil: o de Luiz Antônio Marcuschi, especialmente em relação à questão oralidade/escrita; o de Raquel Salek Fiad, reiteradamente relacionado ao ensino de escrita na escola, sendo seguido por Renilson Menegassi; o de Regina Dell'Isola, inspirada em Marcuschi; o de Maria de Lourdes Matencio, também com preocupações teóricas e pedagógicas; entre outros mais recentes.

D’Andréa e Ribeiro (2010), ao revisarem conceituações de retextualização e reescrita, terminam por sumarizar a discussão da seguinte forma: os teóricos do assunto consideram retextualização uma operação mais radical de "tradução", isto é, a transformação de um texto em outro, inclusive com mudança de gênero, de propósito comunicativo e mesmo de modalidade (oral/escrito). Já a reescrita seria uma mudança de escopo mais interno ao texto, não havendo alterações como as mencionadas para a retextualização. Dessa forma, retextualizar poderia ser uma operação que envolvesse, inclusive, semioses diferentes (imagem, palavra, som, etc.). A reescrita seria uma operação interna a uma semiose (verbal).

Os trabalhos sobre reescrita a que tivemos acesso ${ }^{6}$ trazem, de forma clara, uma preocupação premente com os processos pedagógicos e de ensino/

\footnotetext{
${ }^{5}$ Ver, por exemplo, Seixas (2009), Gonzaga (2010) ou Paiva e Sodré (2005).

${ }^{6}$ Principalmente, Fiad (2001), Marcuschi (2001), Dell'Isola (2007), Menegassi (2001) e Matencio (2002; 2003).
} 
aprendizagem de escrita, sendo então a reescrita (e a retextualização) uma espécie de "método" para o desenvolvimento de habilidades com o texto, especialmente para as séries do ensino básico brasileiro (fundamental e médio). São comuns, inclusive, sugestôes de atividades de produção textual que empregam a retextualização ou a reescrita como oportunidades de compreensão e melhoria dos processos redacionais.

Neste trabalho, estamos diante de um processo de reescrita (não envolvendo retextualização), em um domínio especializado da linguagem, o jornalismo, operado por profissionais que têm o desafio de produzir notícias para o ambiente digital, sem o processo editorial tradicionalmente encontrado na produção da notícia impressa.

Conforme o fluxograma geral que propomos a seguir, a notícia "impressa" ou produzida "ao modo do impresso", passa por etapas mais estanques, especialmente a da escrita, não oferecendo a visualização do processo, isto é, seu making of, ao leitor.

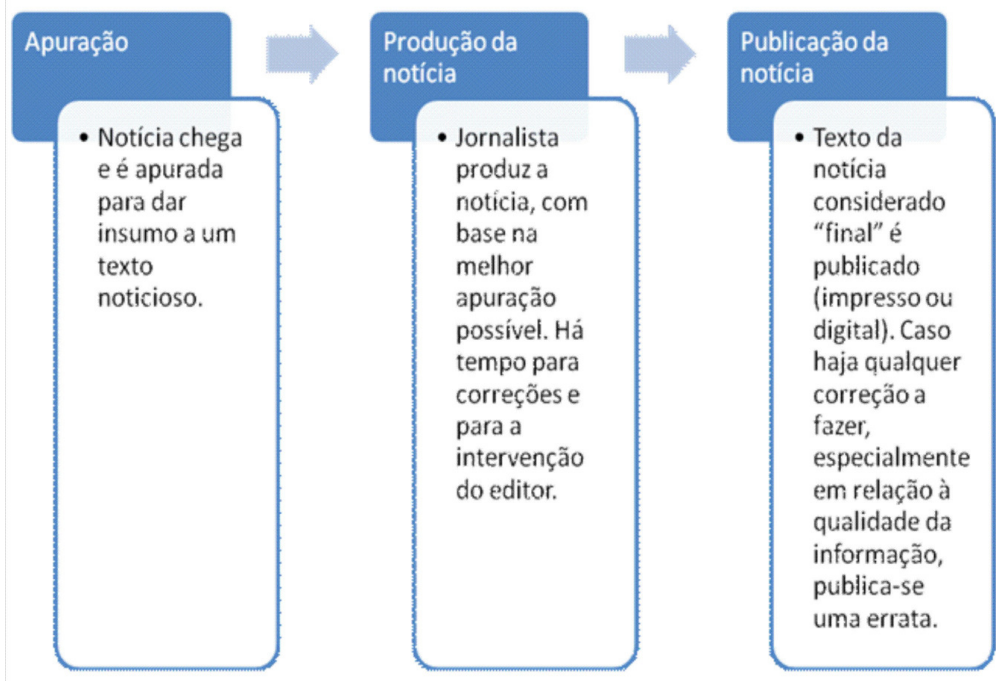

Fluxograma 1: elaborado pelas autoras.

Na próxima representação, pode-se verificar a produção ininterrupta do texto, o que descaracteriza "etapas", mas configura um ciclo recursivo (não mais um fluxo) contínuo de reescritas, de forma transparente, isto é, diante dos olhos do leitor, que vê as alterações do texto e precisa lê-lo também várias vezes, se quiser "acompanhar" o caso. Não há making of e, sim, o descortinamento 
ou a "produção revelada" do texto "enquanto" é produzido. Trata-se, portanto, de uma lógica diferenciada de produção noticiosa impressa, ao que parece com mais compromisso com a atualização constante do que com a correção definitiva do que é noticiado.

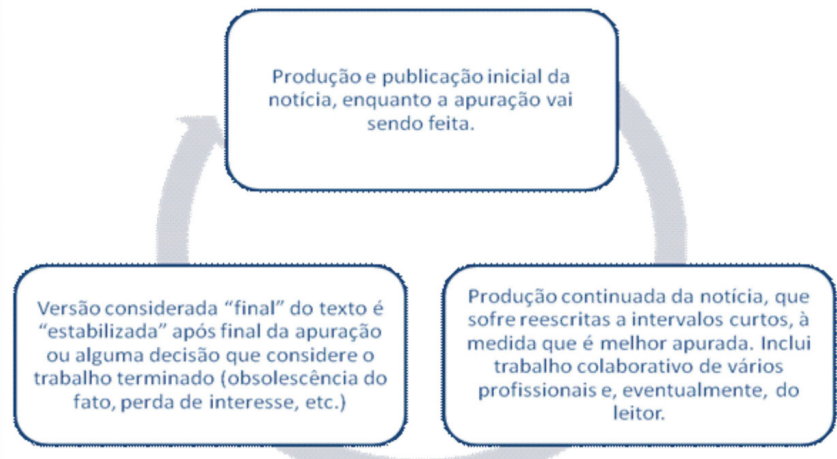

Fluxograma 2: elaborado pelas autoras.

\section{Retextualização e reescrita - aspectos da edição do texto}

Vimos que são vários os elementos que interferem na composição do texto noticioso, entre eles aspectos tecnológicos ligados ao processo de edição, ao suporte de publicação e à forma de circulação do texto. As tecnologias digitais trouxeram mudanças para esse processo, incluindo-se a possibilidade da publicação em tempo real.

Sendo a notícia ${ }^{7}$ um gênero relativamente estável, bastante consolidado na prática jornalística, e protagonista de um domínio profissional, é esperado que haja recomendações e guias que auxiliem aprendizes, especialmente estudantes de Comunicação, a desenvolver esse gênero. Com esse fito existem os manuais que dão diretrizes para a formulação da notícia, sendo a técnica mais conhecida nomeada como "pirâmide invertida".

\footnotetext{
${ }^{7}$ Não vamos aqui nos ater ao que é uma notícia. A estrutura e a composição desse gênero já foram discutidos por Bonini (2003) e em manuais como os de Lage (1986). ${ }^{8}$ A técnica costuma ser apresentada aos futuros jornalistas com perguntas-guias: o quê, quem, onde, como, quando e por quê.
} 
A "pirâmide invertida" consiste em escrever a notícia de forma a priorizar os aspectos principais e mais fundamentais dos acontecimentos, deixando em segundo plano os detalhes e mesmo uma contextualização mais dedicada. Embora essa técnica seja amplamente ensinada e usada, há pesquisadores que a colocam, atualmente, em xeque quando se pensa a webnotícia (caso de Canavilhas, conforme já mencionado).

A produção de textos noticiosos com base na "pirâmide invertida" tem seus defensores e seus detratores, quando o ambiente em questão é a web. Canavilhas $(2001$; 2006) é um dos propositores de um novo modelo redacional para a notícia na web, modelo ao qual ele deu o nome de "pirâmide deitada”. Já Paul Bradshaw, em 2007, propunha um modelo nomeado de "news diamond" (diamante de informação), que empregava não apenas um novo jeito de escrever o texto, mas também o uso de diversos ambientes para encadear a notícia (Twitter, site do jornal, blog, etc.). ${ }^{9}$

De toda forma, esses são modelos, isto é, propostas ainda em experimentação, especialmente em jornais mais "ousados" em suas configurações e linguagens, na atualidade. A maior parte dos jornais, mesmo com suas versōes on-line, mantém os mesmos textos que produzem para os jornais impressos, o que também mantém a "pirâmide invertida" ainda prevalente. A "transposição" de um modo impresso de fazer notícia para um modo web ainda passa por ajustes e tentativas (RIBEIRO, 2009).

O elemento mais fundamental de transformação do texto jornalístico talvez tenha sido a possibilidade de dar a notícia "em tempo real". Aspectos como a apuração e a revisão do texto (ou o cuidado com o "texto final") tornam-se menos importantes do que critérios como a recência e a instantaneidade da informação. Em certos processos editoriais jornalísticos mediados por computador, opera a máxima "publique depois corrija" (D’ANDRÉA, 2011), que guia muitos jornais e revistas on-line, entre outros produtos. Tais mudanças de rotina terminam por afetar a construção da notícia, que passa a ser reescrita diversas vezes, ao longo do dia. Embora o caso analisado aqui não tenha todas as características apontadas para a webnotícia ou a reportagem web, como links no texto, áudio, vídeo, entre outros,

\footnotetext{
${ }^{9}$ Para conhecer essas propostas, ver Canavilhas (2006) e Bradshaw (2007). Ambas estão disponíveis na web. Apenas para adiantar superficialmente, Canavilhas propõe a redação em mais camadas de texto, segmentando a informação; e Bradshaw propõe, além das camadas, vários canais de difusão da mesma informação, encadeados, incluindo-se a interação com o leitor.
} 
alguns elementos são essenciais nas mutações sofridas pelo texto noticioso de alguns anos para cá: a atualização (com publicação) constante e a produção do texto na e para a web, muita vez sequer sem versão impressa.

A reescrita, sobre a qual vamos nos ater aqui, é parte de uma prática profissional recentemente transformada, embora mantenha forte matriz no jornalismo impresso. Trata-se, no entanto, não apenas de uma reescrita necessária ao processo de produção da notícia, como sempre houve, mas de uma reescrita que acontece diante do leitor, passível de acompanhamento e até mesmo de colaboração. Cabe, no entanto, a questão: o meio internet propicia e induz uma retextualização ou uma reescrita?

Se considerarmos, como para Marcuschi (2001), que uma retextualização só se faz com mudança de modalidade (oral/escrito, por exemplo) ${ }^{10}$ ou, com Dell'Isola (2007), para quem só se obtém retextualização com a formulação de um novo texto a partir de um original, ${ }^{11}$ não temos retextualização nas práticas mais ordinárias de webjornalismo e construção da webnotícia. O tipo de mudança textual feita pelos jornalistas, em sua prática diária, nos leva a crer que estamos sempre diante de uma reescrita.

Para mostrar um caso que consideramos típico desse processo de reescrita, que parece afastar uma retextualização, apresentamos uma despretensiosa análise do processo de redação de uma webnotícia, ao longo de um dia, com base em dados coletados em um jornal mineiro, em sua versão na internet. Nossa análise baseia-se, tangencialmente, nas operações de edição mencionadas por Raquel Fiad (1991), que se baseia em Fabre (1986).

Segundo nossa hipótese inicial, a inserção de informaçōes torna-se uma operação intensa na produção da webnotícia, assim como as substituições de alto valor semântico ou o que podemos considerar inserções que visam a aumentar a informatividade ou o detalhamento sobre um fato. Nossa proposta, aqui, é considerar, antes de tudo, que se trate de uma reescrita baseada

\footnotetext{
${ }^{10}$ É importante, no entanto, considerar que o jornalismo opera muito com a retextualização. Uma notícia escrita, em sua primeira apresentação, é resultado da coleta de informações orais com fontes, personagens, etc. A apuração jornalística parte de entrevistas, telefonemas, etc. Sendo assim, a notícia reescrita partiria de uma primeira versão já considerada apenas em sua formulação escrita, ignorandose esse processo multimodal obrigatório, intrínseco ao processo noticioso. Indo mais longe, se pensarmos assim, qual texto escrito não é retextualização?

${ }^{11}$ Para ver uma reflexão despretensiosa, mas esclarecedora, sobre isso, ver d'Andréa e Ribeiro (2010).
} 
na chegada de novos dados à redação (empresa). O segundo elemento que levaremos em consideração é que as mudanças feitas no texto são de caráter incremental, do ponto de vista da composição textual (e mesmo de sua estrutura, que se mantém a mesma). A "pirâmide invertida” pode ser depreendida como técnica de redação, mas o processo redacional é, agora, completamente revelado, o que insere o leitor como alguém que acompanha (e até participa!) a produção texto, de forma transparente, em vez de apenas tomar contato com o produto de um processo opaco de redação.

As modificações do texto webnoticioso vão sendo feitas de forma revelada, à vista do leitor, que pode, inclusive, interferir de forma mais direta na produção da notícia (com um comentário ou uma correção, por exemplo). Não há mudanças drásticas, de modalidade ou de estrutura, mas há inserção de informações, de forma que a notícia vá ganhando unidades significativas, e não apenas uma revisão gramatical, por exemplo (embora esta também ocorra).

\section{Webnotícia - método}

Os processos de construção da notícia produzida na/para a web parecem não diferir muito, de veículo para veículo, ao menos no Brasil. Em razão disso, optamos por acompanhar o processo de produção de notícias em dois jornais mineiros, pioneiros na adesão à versão web, ${ }^{12}$ com o objetivo de coletar notícias factuais em todos os dias da semana. Apenas uma notícia será analisada aqui, dado o espaço limitado do artigo, mas pensamos ser um caso notável em razão de sua tipicidade (BROWN; RODGERS, 2002).

Neste trabalho, apresentamos a análise da reescrita de uma notícia selecionada, reiteramos, devido à sua tipicidade em relação à produção geral de webnotícias. Trata-se, sabemos, de uma análise despretensiosa, mas que pensamos contribuir para a adoção de um conceito e de sistematização da ideia de reescrita no domínio jornalístico, auxiliando-nos, inclusive, na sistematização do trabalho e das práticas laboratoriais (ensino/aprendizagem) dos jornalistas em formação.

Com a ajuda de um software, capturamos notícias que foram sendo publicadas em jornais mineiros e apresentamos uma delas aqui, como um exemplo do processo adotado pelos portais e sites noticiosos contemporâneos.

${ }^{12}$ Os jornais mineiros não estiveram atrás de outros grandes jornais. Data de 1996 a entrada, por exemplo, do Estado de Minas na web. 
Para nos auxiliar na indicação dos elementos que consideramos dignos de atenção, fizemos marcaçôes (colchetes vermelhos) em trechos do texto, que passamos a analisar.

\section{Webnotícia - uma análise}

A notícia que selecionamos para analisar trata de um tiroteio com morte, como se verá mais adiante. Uma troca de tiros entre bandidos e polícia termina em tragédia, o que é considerado noticiável pelo jornalismo local. A cobertura web do acontecimento trata, então, de dar o que Bradshaw (2007) chamaria de "alerta" (embora fora do Twitter) ou o que Canavilhas consideraria o "nível de base", isto é, o lead.

Em apenas três linhas de texto (além do título), uma notícia muito preliminar é publicada, às $13 \mathrm{~h} 09$, tendo como autoras duas jornalistas, Luana Cruz e Karina Novy. O espaço para atualizações do texto já está previsto, assim como o indicativo mais explícito "Aguarde mais informaçôes", abaixo da notícia.

Do ponto de vista da construção do texto, é importante observar alguns itens em relação, por exemplo, à coerência entre informações sobre o fato e à "correção gramatical", ${ }^{13}$ geralmente esperada nesse gênero textual.

O título canônico ${ }^{14}$ informava o leitor sobre um policial ferido em uma troca de tiros que teria ocorrido na capital de Minas Gerais. Na primeira linha da notícia, verifica-se a informação de que o fato teria se dado na cidade de Contagem, na Região Metropolitana de Belo Horizonte. Essa incoerência (e incorreção, do ponto de vista da informação) é relevante no contexto jornalístico. Um leitor com conhecimento enciclopédico poderia detectar,

\footnotetext{
${ }^{13}$ Não nos engajaremos aqui na discussão sociolinguística sobre "correção", norma ou língua padrão. Nosso foco são as alterações feitas no texto, certamente baseadas em diretrizes gramaticais.

${ }^{14}$ Corrêa (1996) classifica os títulos como canônicos e enviesados. Canônicos "são aqueles que trazem a informação mais importante do texto, a sua ideia central, funcionando como uma espécie de resumo do resumo", os canônicos "promovem uma informação de menor importância à categoria de ideia central do texto". Essa escolha discursiva traz diferenças para a compreensão leitora. $\mathrm{O}$ jornalismo faz uso de ambos os tipos de títulos. É só pensarmos nas estratégias empregadas por jornais "sensacionalistas", que enviesam suas manchetes, ou nos jornais mais "sérios", que dão títulos "canônicos".
} 
facilmente, o problema e atribuí-lo à "pressa" de redação e apuração. No entanto, um leitor com menor conhecimento prévio estaria sujeito a "aprender" equivocadamente a relação entre a Região Metropolitana e a capital mineira.

Em relação à correção gramatical, observa-se a falta de uma preposição "de" e uma troca de letras em "augarde", além da redundante expressão "troca de tiros".

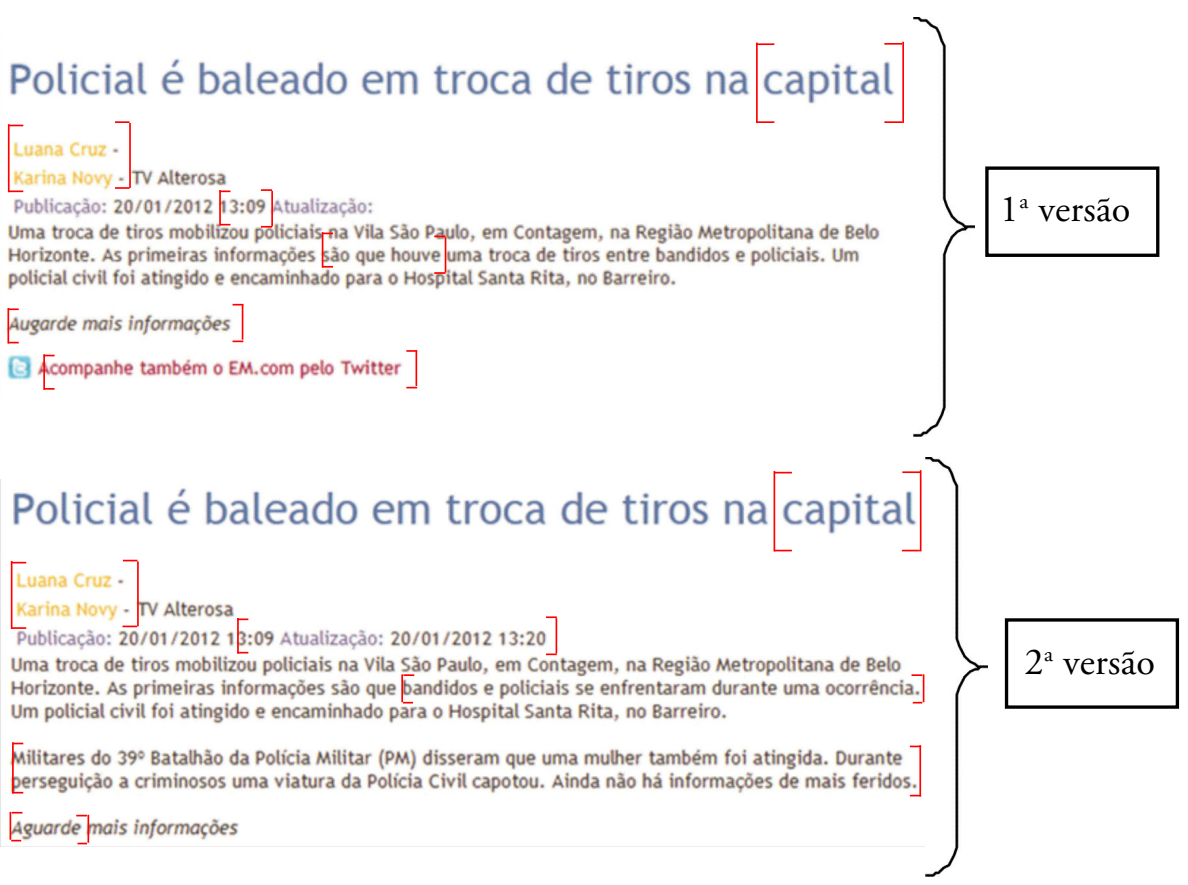

A versão atualizada da notícia, 11 minutos depois, mantém os problemas de coerência da informação, mas corrige a troca de letras do "Aguarde mais informações". As maiores operações, no entanto, dizem respeito à inserção de informações posteriormente apuradas, especialmente na construção de um segundo parágrafo, e à reescrita de uma oração do parágrafo inicial (de "houve uma troca de tiros entre bandidos e policiais" para "bandidos e policiais se enfrentaram durante uma ocorrência”), claramente para substituir a redundância em "troca de tiros", optando por manter a "troca de tiros" como informação nova e uma expressão mais genérica ("enfrentaram”) com função anafórica, em seguida.

Como se verifica, à ocorrência com um policial, na troca de tiros, somam-se outros fatos como uma mulher atingida e o capotamento de uma viatura policial. Diante da possibilidade de obter mais informaçôes e da certeza 
de que o texto estaria sempre inacabado, a modalização é um recurso empregado pelos redatores, de maneira interessante. A seleção de "As primeiras informações são..." e de "Ainda não há informaçōes de mais feridos", isto é, a opção por não serem categóricos nas afirmações abre uma margem que assegura aos jornalistas uma proteção de faces, além da chance de ampliar e melhorar o texto noticioso, agora sem a obrigação de ser exato e final.

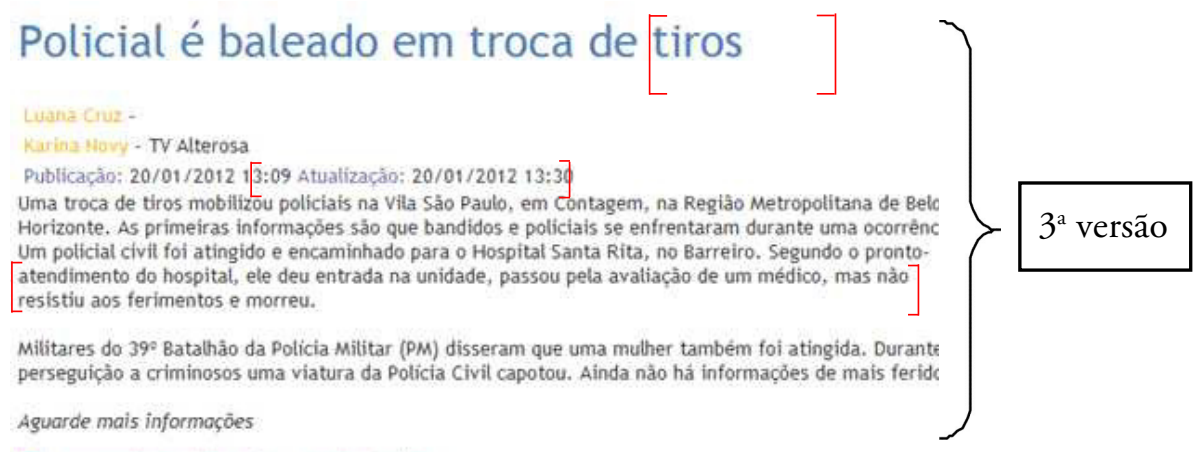

B Acompanhe tambèm o EM.com pelo Twitter

Dez minutos depois da primeira atualização da notícia (e 21 minutos após a publicação inicial), uma terceira versão é apresentada ao leitor, novamente com inserção de trechos e informações, agora no primeiro parágrafo. Incrementalmente, são detalhadas ocorrências relacionadas ao policial atingido no enfrentamento com bandidos e sua morte é, então, anunciada. Nesta atualização, o título é corrigido, o que sana a incoerência sobre o local de ocorrência dos eventos.

A quarta versão do texto (terceira atualização da notícia), seis minutos após a anterior, traz alterações que conferem mais precisão a alguns aspectos da informação, tais como o nome completo do policial morto e sua função na polícia. $\mathrm{O}$ trecho é, então, convertido em um parágrafo à parte. Ainda assim, mantêm-se as modalizações que dão abertura às modificações vindouras da notícia, assim como algumas expressões que tornam o texto impreciso, como "Uma troca de tiros...", "uma ocorrência", "Um policial civil foi atingido...", "um médico". De posse da informação sobre o nome do policial assassinado, os redatores poderiam ter optado por outro tipo de reescrita, como, por exemplo, a substituição de "Um policial civil foi atingido..." por "O policial Sérgio Barbosa Toledo foi atingido e encaminhado para o prontoatendimento do Hospital Santa Rita, no Barreiro, onde foi avaliado por um médico. $\mathrm{O}$ agente da polícia civil não resistiu aos ferimentos e morreu”. A 
ausência de operações mais justas de reescrita terminam por dar ao texto uma característica de "remendo" que não nos pareceu interessante, isto é, o produto que se vai construindo, on-line, vai se tornando um texto com problemas de coesão, às vezes de coerência, embora cumpra seu papel precípuo de oferecer uma informação com agilidade.

\section{Policial é baleado em troca de tiros}

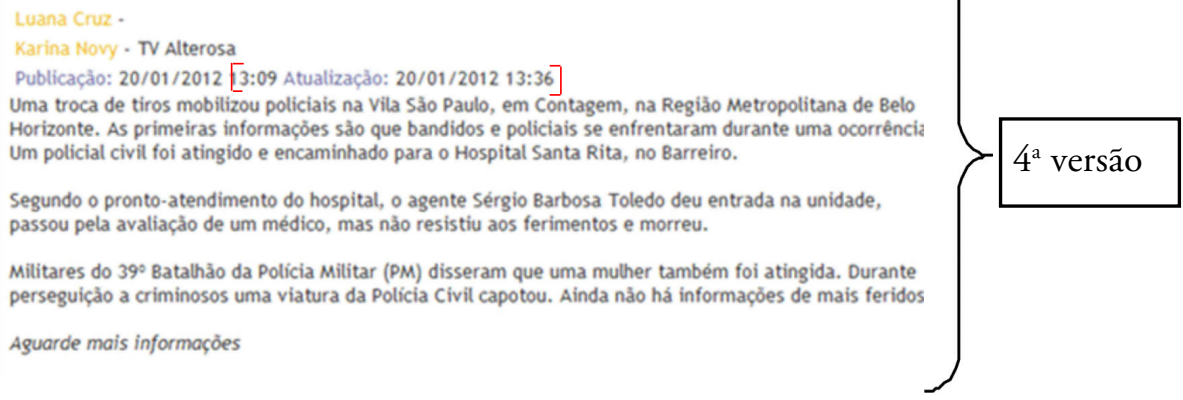

A quinta atualização da notícia, como se vê, é apresentada ao leitor com mais um parágrafo, no qual se informa sobre a mobilização de colegas do policial morto na caça aos bandidos, elemento que não parece ter grande impacto para o fato em si. No entanto, a sexta atualização traz elementos interessantes, do ponto de vista da construção do texto. São inseridas muitas informaçôes, em novos trechos, mas ainda ligados a trechos antigos.

\section{Policial é baleado em troca de tiros}

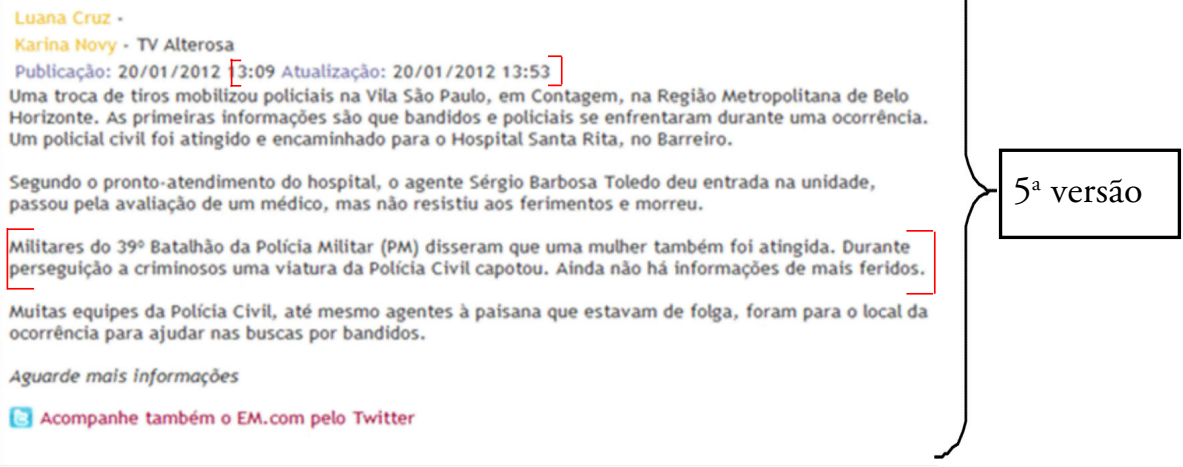

A despeito da manutenção da expressão "Segundo as primeiras informaçōes...”, oriunda da primeira publicação, que relatava apenas uma "troca de tiros entre bandidos e policiais", surgem novas informações ao leitor: 
"suspeitos assaltavam uma empresa na região, quando uma viatura da Divisão de Tóxicos e Entorpecentes passou pelo local e flagrou a ação dos bandidos". Só aí surge a troca de tiros entre policiais e bandidos. A inserção do trecho, já na quinta atualização, mais de uma hora após a publicação inicial, oferece ao leitor melhor ideia de como teve início o fato que culminou com a morte de um policial.

As primeiras informações dadas ao leitor não traziam esses pormenores, considerados interessantes, já que o flagrante da polícia é que disparou o conflito, que teve início em um acaso, já que uma viatura passava por ali fora de uma diligência. No segundo parágrafo, outra informação é inserida: o apelido do policial baleado. A oração é reescrita, de forma mais compacta.

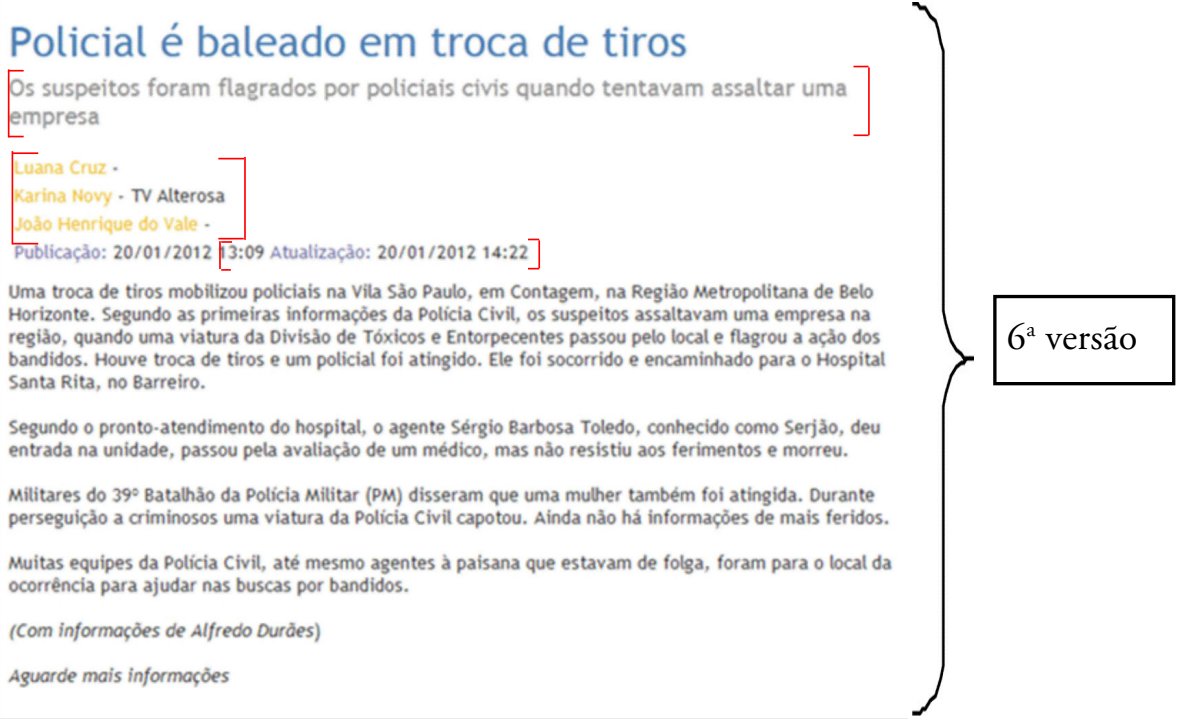

Os elementos que compõem uma notícia factual, ou o paratexto dessa notícia, sofrem alterações nessa versão (6): surge um novo autor do texto, o jornalista João Henrique do Vale, e um subtítulo ("bigode", no jargão) é acrescentado, justamente para explicitar a curiosa situação em que os bandidos foram surpreendidos por uma viatura.

Mesmo com as inserções que a notícia sofre desde sua primeira publicação, não há alteração de fundo em sua estrutura, na ordem dos dados noticiados ou mesmo no tema geral do texto, isto é, pode-se resumir a notícia nas mesmas poucas linhas em que ela fora inicialmente oferecida ao público: um policial morreu em um confronto com bandidos. 


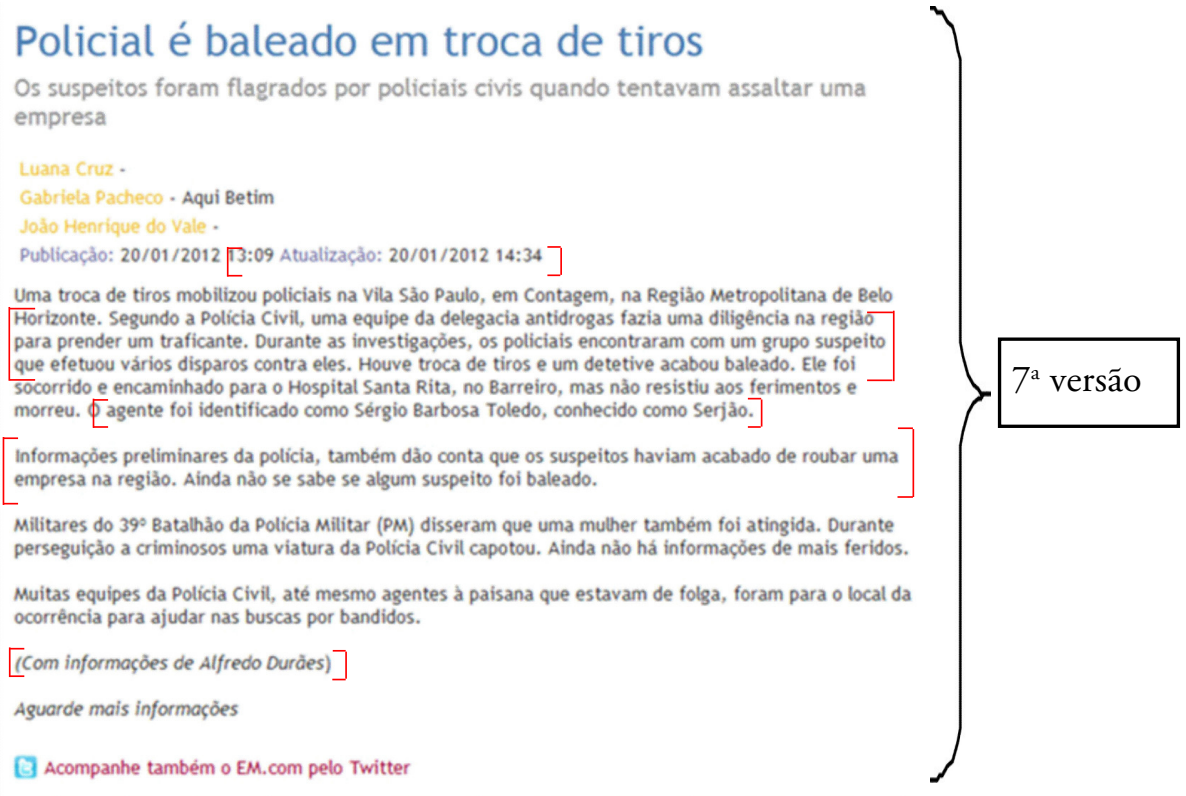

A última atualização do texto, publicada às $14 \mathrm{~h} 34$, quase uma hora $\mathrm{e}$ meia após a notícia inicial, é a que apresenta mais operaçôes de reescrita, com a finalidade, ao que parece, de fazer ajustes propriamente textuais, sem a inserção de dados apurados a posteriori. Há a reescrita de oraçōes inteiras, numa espécie de "varredura" do texto em busca de coesão e correção.

\section{Considerações finais}

As mudanças trazidas pelas tecnologias digitais ao processo jornalístico são importantes. Talvez não tenham chegado a alterar, em sua essência, a característica informativa do texto noticioso, sua estrutura temática ou sua composição (GONZAGA-PONTES, 2012), mas influenciaram a forma como esse texto é produzido e publicado.

Juntamente com isso, alteram-se as práticas do leitor. Aquele leitor de jornais que estava acostumado à leitura matutina ou vespertina de um diário que dava as notícias do dia anterior já não se sente mais tão confortável. Se a televisão, com seu jornalismo "ao vivo", já vinha alterando os modos de recepção das notícias, "envelhecendo" o jornal do dia seguinte já na véspera, a web tratou de acelerar ainda mais esse processo, ao mostrar os fatos noticiáveis no mesmo instante em que eles ocorrem. Já não se trata da informação "ao vivo", mas do "tempo real". 
As práticas do leitor também são alteradas porque ele passa a visitar os jornais digitais diversas vezes ao dia, abandonando um hábito de "fidelidade" a intervalos diários, substituído por visitas frequentes ao portal de notícias a cada hora, por exemplo. É uma leitura que depende de atualizaçôes, reloads, refreshs ou de primir a tecla F5 para recarregar uma notícia que pode estar inacabada e pode, inclusive, depender da participação do "usuário" para ficar melhor. De toda forma, estão lá, ainda mais evidentes, as operações de reescrita, agora reveladas e transparentes.

\section{Referências}

BONINI, Adair. O conhecimento de jornalistas sobre os gêneros textuais: um estudo introdutório. Revista Linguagem em (Dis)curso, Tubarão, v. 2, n. 1, jul/ dez. 2001.

BONINI, Adair. Os gêneros do jornal: o que aponta a literatura da área de comunicação no Brasil? Linguagem em (Dis)curso, Tubarão/SC, v. 4, n. 1, p. 205231, jul./dez. 2003. Disponível em: <http://www3.unisul.br/paginas/ensino/ pos/linguagem/0401/13\%20art \%2011\%20P.pdf>. Acesso em: 27 set. 2010. BONINI, Adair. Veículo de comunicação e gênero textual: noções conflitantes. DELTA. Documentação de Estudos em Lingüistica Teórica e Aplicada, São Paulo, v. 19, n. 1, p. 65-89, 2003a.

BONINI, Adair. Página, seção, notícia, nota: critérios de identificação do gênero no jornal. ABRALIN (Curitiba), Fortaleza, v.1, n. 26, p. 616-618, $2003 \mathrm{~b}$.

BRADSHAW, Paul. A Model for the 21st Century Newsroom: the news diamond. Online Journalism Blog, 2007. Disponível em: <http://onlinejournalismblog. com/2007/09/17/a-model-for-the-21stcentury->. Acesso em: 2 dez. 2010.

BROWN, J. D.; RODGERS, T. Doing second language research. Oxford: Oxford, 2002. (Caps. 1, 2, 3)

CANAVILHAS, João. Webjornalismo. Considerações gerais sobre jornalismo na web. I CONGRESSO IBÉRICO DE COMUNICAÇĀO. Biblioteca On-line de Ciências da Comunicação, 2001. Disponível em: <http://www.bocc.ubi.pt/_esp/ autor.php? codautor=602>. Acesso em: 2 dez. 2006.

CANAVILHAS. João. Webjornalismo: Da pirâmide invertida à pirâmide deitada. Biblioteca On-line de Ciências da Comunicação, 2006. Disponível em: <http://xa.yimg.com/kq/groups/22040972/1450934450/name/canavilhasjoao-webjornalismo-piramide-invertida.pdf>. Acesso em: 11 jun. 2012

CHARTIER, Roger. Textos, impressão, leituras. In: HUNT, Lynn. A nova história cultural. 2 ed. São Paulo: Martins Fontes, 2001. 
CHARTIER, Roger. Os desafios da escrita. Trad. Fulvia M. L. Moretto. São Paulo: Editora Unesp, 2002.

CORRÊA, Hércules Tolêdo. Processos de leitura: a influência do título na construção de macroestruturas textuais. Dissertação (Mestrado em Letras), 209p. Faculdade de Letras, Universidade Federal de Minas Gerais, 1996.

CRUZ, Luana et al. Policial é baleado em troca de tiros. Estado de Minas, 20 jan. 2012.

D’ANDRÉA, Carlos F. B.; Ana Elisa Ribeiro. Retextualizar e reescrever, editar e revisar: Reflexôes sobre a produção de textos e as redes de produção editorial. Veredas on line, 1, p. 64-74, 2010.

D’ANDRÉA, Carlos F. B. Processos editoriais auto-organizados na Wikipédia em português: a edição colaborativa de biografias de pessoas vivas. Tese (Doutorado em Linguística Aplicada). Faculdade de Letras, Universidade Federal de Minas Gerais, 2011.

DELL'ISOLA, R. Retextualização de gêneros escritos. Rio de Janeiro: Lucerna, 2007. FABRE, C. Des variantes de brouillon au cours préparatoire. Études de Linguistique Appliquée, 62, p. 59-79, Avril-Jun. 1986.

GONZAGA, Camila C. Santos. Webnotícia: realinhamentos da produção jornalística na web. 3o SIMPÓSIO HIPERTEXTO E TECNOLOGIAS NA EDUCAÇÃO. UFPE, Anais... 2010. Disponível em: <http://www.ufpe.br/ nehte/simposio/anais/Anais-Hipertexto-2010/Camila-Cristina-SantosGonzaga.pdf>. Acesso em: 11 jun. 2012

GONZAGA-PONTES, Camila. Aguarde mais informaçôes. Uma análise da webnotícia com base na releitura da estrutura da notícia de Teun van Dijk. Dissertação. (Mestrado em Estudos de Linguagens). Centro Federal de Educação Tecnológica de Minas Gerais, 2012.

JOVEM PAN. Manual de radio jornalismo. São Paulo: Ática, 1993.

LAGE, Nilson. Linguagem jornalística. 2 ed. São Paulo: Ática, 1986.

MARCUSCHI, Luiz Antônio. Da fala para a escrita. Atividades de retextualização. 2 ed. São Paulo: Cortez, 2001b.

MARQUES DE MELO, José. Gêneros jornalísticos no Brasil: o estado da questão. XXXII CONGRESSO BRASILEIRO DE CIÊNCIAS DA COMUNICAÇÃO. Anais... Curitiba, 4 a 7 de setembro de 2009.

MATENCIO, M. L. M. Atividades de retextualização em práticas acadêmicas: um estudo do gênero resumo. Scripta, Belo Horizonte, v. 6, n. 11, p. 25-32, 2002. 
MATENCIO, M. L. M. Referenciação e retextualização de textos acadêmicos: um estudo do resumo e da resenha. Anais do III Congresso Internacional da ABRALIN, março de 2003.

MENEGASSI, R. J. Da revisão a reescrita: operações lingüísticas sugeridas e atendidas na construção do texto. Mimesis, Bauru, v. 22, n. 1, p. 49-68, 2001. MIELNICZUK, Luciana. Características e implicaçôes do jornalismo na web. II CONGRESSO DA SOPCOM, Anais... Lisboa, 2001. Disponível em: <http:/ /www.facom.ufba.br/jol/pdf/2001_mielniczuk_caracteristicasimplicacoes.pdf>. Acesso em: 2 dez. 2006.

MOHERDAUI, Luciana. Guia de estilo web. 3 ed. São Paulo: Senac, 2007.

NASCIMENTO, Patricia Ceolin. Técnicas de redação em jornalismo. São Paulo: Saraiva, 2009.

PATERNOSTRO, Vera Iris. O texto na TV. 2 ed. São Paulo: Campus, 2006.

RIBEIRO, Ana Elisa. Notas sobre o conceito de "transposição" e suas implicações para os estudos da leitura de jornais on-line. Em Questão, v. 15, n. 2, 2009.

RODRIGUES, Bruno. Webwriting. São Paulo: Brasport, 2006.

SALAVERRÍA, Ramon. Redacción periodistica en internet. Espanha: Eunsa, 2005. SEIXAS, Lia. O lugar da narrativa no hipertexto jornalístico: uma análise do conceito de narrativa na webnotícia. Biblioteca On-line de Ciências da Comunicação, 2009. Disponível em: <http://bocc.ufp.pt/pag/seixas-lia-lugarda-narrativa-no-hipertexto-jornalistico.pdf $>$. Acesso em: 11 jun. 2012.

SODRÉ, Muniz; PAIVA, Raquel. O que é mesmo uma notícia? XIV ENCONTRO ANUAL DA COMPÓS, Anais... 2005. Disponível em: <http://scholar.googleuser content.com/scholar?q=cache:6bqf-YMxZ00J:scholar.google.com $/$ +not $\% \mathrm{C} 3 \%$ ADcia+paiva+sodr\%C3\%A9\&hl=pt-BR\&as_sdt=0>. Acesso em: 11 jun. 2012.

Recebido em 20/07/2012. Aprovado em 01/10/2012. 